Полина Шмарова

\title{
К ВОПРОСУ О ФОРМИРОВАНИИ ИДЕИ УНИВЕРСАЛЬНОЙ ГРАММАТИКИ
}

Резюме. Под именем универсальной, или, иначе, философской грамматики в истории мысли о языке понимают концепцию, согласно которой язык предстает не как совокупность правил, а как система, организованная вокруг определенных принципов мышления. Статья посвящена вопросу о предпосылках формирования идеи универсальной грамматики в Европе XIIXIII веков. В настоящем тексте дается краткий обзор истории грамматики, начиная с V века до н. э. до XIII века н. э. Рассматриваются предпосылки и особенности формирования идеи универсальной грамматики в контексте интеллектуальной ситуации XI-XIII веков (заново открытые тексты греческих и арабских авторов, университетский тип учености, особое положение факультета свободных искусств, схоластика как новая философия).

Ключевые слова: универсальная грамматика, Парижский университет, схоластика, модисты.

\section{Polina Shmarova}

\section{ON THE FORMATION OF UNIVERSAL GRAMMAR}

Abstract. In the history of thought about language, Universal - or Philosophical - Grammar has been understood as a concept according to which language is not considered to be a set of rules determining correct word usage, but a system based on certain principles of thought. This article examines the premises of shaping the concept of Universal Grammar in Europe in the $12^{\text {th }}$ and $13^{\text {th }}$ centuries, providing a brief survey of the history of grammar from the $5^{\text {th }}$ century BC to the $13^{\text {th }}$ century AD with a special focus on a third grammar, namely Modist philosophical and grammatical theory. The paper also investigates the premises and peculiarities of the concept of Universal Grammar within the context of the contemporary intellectualism in the $12^{\text {th }}$ and $13^{\text {th }}$ centuries, characterized by the rediscovery of texts by Greek and Arabic authors, an academic approach, the exceptional position of the Liberal Arts Faculty, and scholasticism as a new philosophy.

Keywords: universal grammar, University of Paris, scholasticism, modists.

Несмотря на то что ХХ век дал нам ряд фундаментальных исследований, посвященных истории лингвистики Средних веков, большинство из них проведены учеными-лингвистами и носят более исторический, нежели философский характер. Достаточно упомянуть монографию Я. Пинборга «Die Entwicklung der Sprachtheorie im Mittelalter», в которой он представил обстоятельный анализ эволюции средневековой терминологии и теории синтаксиса с XI по $\mathrm{XV}$ века, а также проследил развитие теории модистов от возникновения, до периода затухания под влиянием грамматиков-номиналистов. Несомненный интерес также представляет труд Ф. Динеена «An Introduction to General Linguistics», в котором убедительно показана степень влияния Аристотеля на Средневековую грамматическую теорию. Нельзя обойти вниманием и корпус

${ }^{1}$ Шмарова Полина Сергеевна - магистр философии, независимый исследователь. Polina Shmarova, Master of Philosophy, independent researcher. pol-kamka@mail.ru 
сочинений Г. Л. Берсилл-Холла, включающий несколько работ по грамматике модистов: «Speculative Grammars of the Middle Ages», «Thomas of Erfurt. De modis significandi sive Grammatica speculativa».

В русскоязычной литературе философско-грамматическому учению модистов обычно отводят главу в учебниках по истории лингвистики. Хотя с 80-х годов XX века, начали выходить специальные статьи, посвященные отдельным аспектам грамматической теории, их количество, на взгляд авторов, нельзя назвать исчерпывающим.

Кроме того, будет немаловажным отметить, что к учению модистов в разное время в своих философских сочинениях обращались Чарльз Пирс, Мартин Хайдеггер, Карл-Отто Апель, Умберто Эко. Однако лишь одна монография, на данный момент, полностью посвящена истории идеи универсальной грамматики - это труд А. Л. Савельева «История идеи универсальной грамматики (с древнейших времен и до Лейбница)». В монографии философско-грамматическое учение модистов обозначено как первое разработанное учение в русле идеи об универсальной грамматике.

Настоящая статья посвящена вопросам формирования грамматики как теоретической науки (в противоположность искусству) в логико-философском контексте Европы XI-XIII веков. Мы связываем рождение теоретической грамматики (призванной не учить, а объяснять) с деятельностью грамматиков модистического направления, университетских ученых, трудившихся в Парижском университете XII-XIII веков.

Модисты стремились построить грамматику на твердых основаниях разума, это означало, в частности, очищение грамматики от всего случайного, привходящего. Грамматики модистического направления стремились создать такую науку о языке, в которой все следствия с необходимостью выводятся из первоначал, и полагали модусы обозначения (modi significandi) такими универсальными началами грамматики. Важно подчеркнуть, что речь в такой теории идет не о национальном языке, а о языке как таковом. Вывод о единстве грамматического строя всех языков делается модистами исходя из представления об универсальности законов мышления - логики. «Логика одна и та же у всех, следовательно, и грамматика» (цит. по: Апполонов 2017: 53), писал Иоанн Дакийский. Оформление грамматики в отдельную науку ${ }^{2}$ совпадает, таким образом, с появлением идеи универсальной грамматики, философской концепции, стремившейся дать объяснения правилам и определениям языка, вскрыть его внутреннюю структуру.

Изучение обстоятельств формирования учения модистов, по нашему убеждению, способно открыть новые перспективы в философском осмыслении идеи универсальной грамматики как философской концепции. Она родилась в

2 Подробнее об этом далее. 
среде интеллектуалов нового типа - университетских преподавателей, а деятельность модистов напрямую связана с Парижским университетом XIII века: большинство представителей этого направления были магистрами искусств и преподавателями факультета искусств Парижского университета.

В этой связи важно осветить интеллектуальную ситуацию того времени. Появление интеллектуала в средневековой Европе связано с расцветом городов, развитием промышленности (ремесел), расширением торговых связей со странами Востока - Византией, Дамаском, Багдадом. «Вместе с пряностями и шелком на христианский Запад пришли рукописи, несущие греко-арабскую культуру» (Ле Гофф 2003: 14) — замечает Ле Гофф.

Научным языком Европы XII века была латынь. Арабские оригиналы, арабские версии греческих текстов, греческие оригиналы необходимо было переводить, поэтому интеллектуальный подъем был связан прежде всего с переводческой деятельностью. Часто переводы текстов делались совместными усилиями интеллектуалов Востока и Запада, таким образом создавалось общее интеллектуальное поле. «Заполнялись лакуны в латинском наследии западной культуры - в области философии и прежде всего науки. Математика Эвклида, астрономия Птолемея, медицина Гиппократа и Галена, физика и логика Аристотеля - вот огромный вклад этих тружеников» (Ле Гофф 2003: 17).

Крупнейшим центром усвоения новой интеллектуальной культуры становится Париж. По замечанию Э. Жильсона, «начиная с XII века, Париж и его школы пользуются всеобщей известностью, особенно в том, что касается преподавания диалектики и теологии» (Жильсон 2015: 255). Это связано с расцветом образовательной среды, обилием философских школ, привлекавших во Францию студентов из Англии, Германии и Италии. Достаточно вспомнить таких видных учителей того времени, как Пьер Абеляр, Гильом из Шампо, св. Бернард Клервоский, Гуго Сен-Викторский, Бернард Шартрский.

Интеллектуал XII века - это горожанин, ремесленник. «Его задача изучение и обучение свободным искусствам» (Ле Гофф 2003: 53). Иными словами, важно не только познание, но и производство, интеллектуальная деятельность осознается как профессия. Из этого следует, что знания должны не просто накапливаться, но передаваться и использоваться. «Как человек ремесла, интеллектуал сознает, что его профессия требует подготовки. Он признает необходимую связь между наукой и преподаванием»- отмечает Ле Гофф (2003: 54).

Такое самоощущение интеллектуалов того времени приводит к формированию корпораций студентов и преподавателей, то есть созданию университета. Как отмечает Э. Жильсон, в развитии университетской корпорации были заинтересованы одновременно и французская королевская власть, и папская. С одной стороны, обилие иностранцев, прибывших для изучения наук, 
способствовало росту влияния французской монархии за рубежом, поэтому власть была заинтересована в защите прав студентов, обеспечении их безопасности и «духовной независимости» (Жильсон 2015: 297). С другой стороны, папская власть видела в университетской корпорации мощный инструмент распространения религиозной истины на весь христианский мир.

Университет как корпорация, в свою очередь, стремился обособиться как от церковных, так и от светских властей (боролся за право преподавать, иметь собственную территорию, получать плату и стипендии), самым действенным оружием в борьбе за независимость была забастовка. Так, Парижский университет обретает самостоятельность в 30-х годах XIII века, после кровавых стычек студентов с городской полицией. Ж. Ле Гофф пишет: «В одной из стычек несколько студентов были убиты полицейскими. Большая часть университета объявила забастовку и удалилась в Орлеан. На протяжении двух лет в Париже почти не было занятий. Лишь в 1231 году Людовик Святой и Бланка Кастильская торжественно признали независимость университета, возобновили и расширили те привилегии, которые были признаны Филиппом-Августом в 1200 году» (Ле Гофф 2003: 60).

Для нашего исследования важно очертить внутреннюю организацию Парижского университета. Он состоял из четырех факультетов: Свободные искусства, Право, Медицина и Теология.

Факультет искусств - пропедевтический, на нем проходило обучение семи свободным искусствам (грамматика, риторика, диалектика, арифметика, музыка, геометрия, астрономия), предшествующее поступлению на высшие теологический, медицинский и юридический факультеты. Поскольку это был самый многолюдный факультет, внутри него преподаватели и студенты объединялись в нации - группы по месту рождения. Во главе факультета стоял избираемый на триместр ректор (к концу века ректор факультета свободных искусств станет главой университета). Три высших факультета управлялись мэтрами, или регентами, во главе с деканом.

Обучение в университете начиналось с поступления на факультет искусств и длилось шесть лет (за первые два года обучающийся получал степень бакалавра, а еще через четыре - доктора). Далее приблизительно шесть лет на факультете медицины и права. Следующим шагом было поступление на факультет теологии, там обучение длилось дольше всего - восемь лет. То есть полный курс обучения занимал 15-16 лет.

Основными методами обучения были лекция и диспут. Лекция предполагала чтение и объяснение текстов (Аристотеля, Цицерона, Священного писания, Августина и отцов церкви), то есть комментирование. На диспутах же происходил своего рода поединок студентов, строящийся на подборе аргументов «за»и «против» по сформулированному мэтром вопросу. Результаты таких диспутов в дальнейшем использовались для целей обучения. Что касается 
комментариев, мы знаем их, например, по «Комментариям к Сентенциям» св. Бонавентуры, Дунса Скота, Уильяма Оккама. В результате особой университетской организации не только произошла систематизация и распространение знания, но и окончательно сформировался метод, вошедший в историю мысли под именем схоластики ${ }^{3}$ (достижение целей апологетики римского католицизма средствами античной диалектики).

Здесь следует подробнее остановиться на схоластике как «новой философии», базирующейся на латинской патристике и античной диалектике. Новая она по отношению к античной, строившейся также на теологии и диалектике (см.: Савельев 2006). В качестве основных отличий можно назвать ее экзегетический характер, а также апологетически-полемическую направленность, унаследованную от патристики. История схоластики охватывает около шести веков, в которых можно выделить два периода (до и после формирования университетов и крестовых походов на Восток). Первый - с XI по XII век, на этом этапе формируется такой жанр, как комментарий (от патристики его отличает преобладание диалектических методов), происходит знакомство с ранее неизвестными трудами Аристотеля. K первому периоду исследователи относят Ансельма Кентерберийского, Петра Абеляра, Гильома из Конша, Гюго Сан-Викторского, Петра Ломбардского. Второй этап, так называемая высокая схоластика, начинается с конца XII века, в это время закрепляется основной догмат римского католицизма и перипатетический метод, институционально оформляется университет. Можно назвать таких авторов этого периода, как Альберт Великий, Фома Аквинский, Дунс Скот.

Признанным центром «новой философии» в Западной Европе XIII века был Парижский университет. Это связано с особенной программой факультета искусств: устав Парижского университета от 1255 года (Жильсон 2015: 308) включил в программу факультета искусств изучение всех доступных сочинений Аристотеля по логике, физике и метафизике: «О душе», «О небе и земле», «О чувствах и чувственно воспринимаемом», «О памяти и воспоминании», «Аналитика» (первая и вторая), «Топика», «О софистических опровержениях». Кроме этих книг, предписывались «Книга о шести началах», «Книга о причинах», «О седмицах» Боэция. На первое место выходит изучение аристотелевской диалектики, что по сути превратило факультет искусств в философский факультет.

Однако, как отмечает Э. Жильсон, Парижский университет разрывался между двумя тенденциями: с одной стороны, он мог стать центром чисто научных исследований, с другой - «поставить исследования на службу настоящей

\footnotetext{
${ }^{3}$ История схоластики прослеживается с XI века, однако основное догматическое содержание установилось к началу ХІІІ столетия (то есть синтез перипатетической методологии науки и римского католицизма).
} 
интеллектуальной теократии» (Жильсон 2015: 297). Иными словами, существовал конфликт между факультетом искусств, на котором активно изучался корпус сочинений Аристотеля, и теологическим факультетом. Основное различие между теологическим факультетом и факультетом свободных искусств состояло в том, что на факультете искусств не допускалось обсуждение теологической проблематики (Лисанюк 2006).

Ярким проявлением первой тенденции служит парижский аверроизм, требовавший свободы «преподавать логику, физику и этику Аристотеля, не заботясь ни о состоянии других дисциплин, ни о высших интересах теологии» (Жильсон 2015: 298). Теологический факультет, напротив, не стремился порывать с традицией. Теология на тот момент, как отмечает Э. Жильсон, «представляла собой августинизм, не чурающийся помощи аристотелевской диалектики» (Жильсон 2015: 298). Представители этого движения - убежденные августинианцы: Александр Гэльский, св. Бонавентура, Этьен Тампье. Примирить враждующие стороны сможет к концу века томистский аристотелизм, перестроивший традиционную теологию с позиций аристотелевского метода.

Такой была интеллектуальная ситуация в Парижском университете XIIXIII веков. На фоне возросшего интереса к диалектике Аристотеля, средневековые интеллектуалы стали уделять меньшее внимание другим шести искусствам, а в частности - грамматике. Грамматика (как изящная словесность) изучается в той мере, в какой необходимо знание латыни в качестве языка науки. «Появляется культура нового типа 〈...〉 эту культуру формирует изучение логики и философии Аристотеля, а увенчивает изучение теологии, методика которого исходит опять же из этой логики и философии» (Жильсон 2015: 304). Отныне именно «первая философия» задает общие принципы и методы познания (находить единое во многом, отделять от него случайное), а также ориентацию на «рассмотрение собственной природы вещей» (Апполонов 2017: 51). А в качестве метода полагается «извлечение и обоснование грамматических норм из логических систем и метафизических теорий о природе реальности» (Апполонов 2017: 52).

Философско-грамматическое учение модистов называют третьей грамматикой, обращение к предшествующим двум позволит нам лучше понять своеобразие модистической доктрины.

Рождение грамматики (как науки о правильной речи) непосредственно связано с возникновением письма: устную речь нужно было адекватно передавать на письме, для этого требовалось ввести словесные знаки и правила, регулирующие их употребление. Институализация письма связана с зарождением государственности: первые грамматики были призваны дать правила письма и чтения для адекватной передачи информации, связанной с учетом имущества, сбором налогов и тому подобным. K этому же периоду относится 
создание словарей, призванных закрепить за звуковым образом слова его письменный знак. Первые грамматики различаются в зависимости от того, какая система письма была присуща той или иной культуре. Например, в идеографической системе письменные знаки обозначают целые слова, в слоговой слоги, в алфавитной - буква соответствует звуку. В качестве примеров первых идеографических грамматик можно назвать древнеегипетскую и шумерскую грамматики. Они включали знаки трех типов: словесные, слоговые и детерминативы, призванные классифицировать письменные слова как части речи. В основание деления слов на классы были положены соображения практического характера (классификация объектов для их учета). В дальнейшем словесные знаки заменялись слоговыми, среди первых слоговых систем финикийский и арамейский силлабарии, корейское и японское слоговое письмо. Слоговое письмо не имело знаков для обозначения гласных, что не позволяло читать неизвестные ранее тексты. Эту проблему решает алфавитная система древних греков. Введение букв для гласных позволило передавать «саму звуковую речь» (Савельев 2006: 33). Такая фонетизация изменила представление о материальной природе слова: деление слов на слоги, а слогов на буквы. Окончательное оформление греческой грамматики относится к концу V века до Р. Х. и связано с реформами Архина, узаконившими 24-буквенную алфавитную систему.

Таким образом, характерными чертами первой грамматики является, вопервых, случайный характер языковых знаков и опора на традицию их употребления, а во-вторых, представление о буквах (звуках) как началах грамматики. Именно за отсутствие теоретических обоснований начал грамматики первая грамматика критиковалась модистами, стремившимися все следствия выводить из первоначал.

Вторая грамматика формируется к концу III века до н. э. и связана с деятельностью сообщества библиотекарей-филологов Александрийской библиотеки: Зенодота из Эфеса, Аристофана Византийского, Аристарха Самофракийского, Дионисия Фракийского. Грамматика александрийцев основывалась на сочинениях стоиков и языковой теории Аристотеля. Самым известным изложением грамматики александрийцев является сочинение Дионисия Фракийского «Наука грамматики». В нем грамматика «представляется не наукой о буквах, а „опытным знанием о большей части того, что говорится у поэтов и писателей“‘ (Савельев 2006: 84) и содержит шесть разделов, посвященных искусству чтения вслух, исследованию тропов и композиции текста, объяснению неясных слов и исторических отсылок, выявлению происхождения слов, изучению аналогии, критическому разбору поэзии. Здесь же содержится учение о восьми частях речи: имени, глаголе, причастии, члене, местоимении, предлоге, наречии, союзе. «Общий план, таким образом, состоит в восхождении от 
особенностей произношения к буквам, слогам и затем к словам, которые разделяются на части речи» (Савельев 2006: 85). По отношению к предшествующим грамматическим разработкам новации александрийцев заключались в выделении причастия, предлога и местоимения, а также в учении о свойствах частей речи.

Таким образом, на этапе второй грамматики сохраняется учение о буквах как началах речи, а также ориентация на чтение и письмо, но формируется отделение языковой теории от диалектики. Как отмечает А. Л. Савельев, александрийцы использовали в качестве основного принципа аналогию, что привело к «выделению семантически незначащих феноменов, которые не могли быть выделены в диалектике» (Савельев 2006: 87). Это привело к расширению области случайного в теории грамматики. На этом же этапе создается учение о частях речи, которое будет заимствовано модистами практически без изменений (разница лишь в поиске оснований), однако разработанной теории синтаксиса на этом этапе еще нет.

Яркие представители этого этапа - создатель учебников «Ars minor» и «Ars major» по латинской грамматике Донат (IV век) и великий компилятор Присциан (VI век). Труд Доната «Ars minor» использовался для преподавания и был весьма популярен на протяжении всего средневековья (с VI по XV века по нему преподавали в школах), «Ars major» представлял собой более глубокое и обстоятельное изложение классической латыни. Книга Присциана отличалась большей глубиной и вниманием к вопросам теории: «В своем труде Присциан опирался на авторитет и мнения греческих ученых, особенно Аполлония Дискола, в значительной мере создавая свое описание латинского по образцу греческой системы, заимствованной в свою очередь Аполлонием Дисколом у Дионисия Фракийца. В своем труде Присциан сохранил 8 частей речи, компенсируя отсутствие определенного артикля в латинском признанием латинских междометий отдельным классом слов» (Грошева 1985: 210). Однако важно подчеркнуть, что труды Доната и Присциана не отличаются новаторством в подходе, а напротив, бережно сохраняют грамматическую традицию древних.

Начиная с XII века средневековая грамматическая наука обретает своеобразие. Это связано с распространением трудов Аристотеля, оформлением схоластики и особым статусом факультета искусств. Под влиянием логики грамматика постепенно превращается в спекулятивное исследование, «с этого времени наметился разрыв между практическим и теоретическим подходами к грамматике; учебные пособия, главным достоинством которых была доступность и простота, стали составляться отдельно от теоретических трактатов по грамматике» (Грошева 1985: 218). Отныне вместо ссылки на авторитет классиков, грамматики стремятся решать грамматические проблемы с помощью логических правил. Как отмечает И. А. Перельмутер, отныне грамматикам 
простое описание явлений языка представляется недостаточным, «они стремятся к более глубоким, строгим, безупречным с логической точки зрения определениям языковых явлений, а также к объяснениям, к установлению причин возникновения тех или иных фактов языка» (Перельмутер 1991: 11).

Э. Жильсон называет такую логицизацию языкознания настоящей революцией в области грамматического знания: «отказываться в грамматике от принципа авторитета, чтобы заменить его демонстрацией правил с указанием их причин, означает превращать это искусство в науку, отличную от других, в том числе и от логики» (Жильсон 2015: 305). Грамматика теперь существует в двух формах: как подготовительная ступень к обучению в университете и как грамматика «логиков, обучающих свободным искусствам» (Жильсон 2015: 308). Отныне грамматика становится философским введением к изучению логики, вместо того, чтобы быть инструментом работы с античными литературными шедеврами.

Авторы XIII века обращают внимание на то, что в грамматике наличествует два рода проблем: одни связаны с грамматиками конкретных языков, другие с универсальной структурой, общей основой всех языков. «Структура разума навязывает языку определенные способы выражения, обозначения, которые должны соблюдаться во всех языках, несмотря на особенности каждого» (Жильсон 2015: 306). Традицию, стремившуюся построить априорную науку о языке, в истории мысли принято называть логикой языка или спекулятивной грамматикой. Наиболее завершенное выражение в Средние века она находит в деятельности ученых-грамматиков модистического направления. По замечанию Берсилл-Холла, именно в этот период была предпринята попытка создания «всеобъемлющей теории языка, которая является также теорией семиотики, так как грамматика была явно базисом, на котором развивались главные семиотические проблемы» (цит. по: Грошева 1985: 217). К представителям течения относят Мартина Датского, Боэция Датского, Иоанна Датского, Радульфа Бретонского, Сигера из Куртрэ и, наконец, Фому Эрфуртского, систематизировавшего учение в «Трактате о модусах обозначения».

Модистов в теории грамматики в первую очередь интересовало то, как формируются понятия, то есть то, как мы познаем вещь. Вещь обладает некими свойствами, познать эти свойства мы можем только, сформулировав суждение о них, при этом такое суждение будет подчиняться правилам языка. Например, познать нечто как бегущее можно только сказав: «Это бежит». Поэтому в основе спекулятивной грамматики - представление о трех типах модусов: существования, понимания, обозначения.

Модусами существования обозначали «все свойства вещи, существующей вне сознания» (Бокадорова 2000: 430), при этом речь не идет о сущности, но только о том, что может быть дано нам непосредственно, как познающим. 
Модусы понимания «существуют в познанной вещи как в субъекте, а в сознании - как познанное в познающем» (Бокадорова 2000: 433). Иными словами, это модусы существования, опосредованные сознанием. Модус обозначения определяет «отнесенность названия данного явления к той или иной части речи» (Перельмутер 1991: 30), то есть модус обозначения отражает определенный модус существования этой вещи, так, как это выражается в грамматическом строе речи. Например, слова «дыхание» и «дышать» обозначают одно и то же (имеют одно предметное значение), но отличаются по способу обозначения (демонстрируют различные модусы существования вещи, по-разному соотносятся с остальными членами предложения). «Таким образом, посредством своего значения слово обозначает саму вещь, а посредством модуса обозначения со-означает еще и модус существования этой вещи» (Савельев 2006: 163). Поэтому подлинным предметом изучения полагалось не лексическое, а грамматическое значение слова, модисты концентрировались на поиске первоначал, управляющих грамматическим строем речи. Грамматический строй в учении модистов представляет собой строгую конструкцию, где все члены взаимообусловлены логической необходимостью. Например, синтаксические сочетания обусловлены модусом обозначения слов, входящих в них.

Модисты были первыми учеными, разработавшими на основе модусов обозначения и учения Аристотеля о четырех причинах подробную теорию синтаксиса. В основание теории синтаксиса спекулятивные грамматики полагали три свойства речи: конструкцию («соединение членов при помощи модусов обозначения, созданное разумом для выражения сложного понятия» (Савельев 2006: 170)), согласование («предполагает не сходство соответствующих модусов обозначения, а определенное отношение» (Савельев 2006: 173), например согласование падежа имени и залога глагола) и завершение, благодаря которому составлялось законченное предложение.

Завершенной в теории модистов могла называться только конструкция подлежащего со сказуемым, согласованная надлежащим образом. В итоге в науку о языке вводится различение подлежащего и сказуемого, дополняющее различение имени и глагола, а не заменяющее его.

Мы видим, что учение модистов содержательно принципиально отлично от предшествовавших грамматик и представляет собой первое грамматическое учение, сформированное с позиций теории (а не служащее целям обучения). Оно формировалось в тесной связи с логикой, однако это не логическое, а собственно грамматическое учение с хорошо очерченным предметом: «предмет грамматики - знаки вещей» (Фома 2006: 294). При этом грамматическое учение модистов выходит за рамки исследования проблем латинского языка, а рассматривает язык в целом, нацелено на поиск универсальных принципов 
мышления, управляющих грамматическим строем речи. Философско-грамматическое учение модистов - это первое в истории мысли учение, разработанное в русле идеи об универсальной грамматике.

Изучение философско-грамматического учения модистов (его предшественников, особенности формирования), а также культурных и философских предпосылок появления идеи универсальной грамматики способно, по мнению автора, открыть новые перспективы в философском осмыслении идеи универсальной грамматики с позиций философской науки XXI века.

\section{Литература}

Апполонов 2017 - Апполонов A. В. «Спекулятивная грамматика» Фомы Эрфуртского и современность: случай семиотики Чарльза Пирса // Логос. 2017. Т. 27, № 6. С. $139-152$.

Бокадорова 2000 - Бокадорова Н. Ю. Грамматика и метафизика модистов как явление позднесредневековой культуры // Логический анализ языка. Языки этики / под ред. Н. К. Рябцевой, Т. Е. Янко, Н. Д. Арутюновой. М., 2000. C. $427-436$.

Грошева 1985 - Грошева A. В. Грамматические учения западноевропейского средневековья // История лингвистических учений. Средневековая Европа. М.: Наука, 1985. С. 208-243.

Жильсон 2015 - Жильсон Э. Философия в средние века: от истоков патристики до конца XIV века / под ред. С. С. Неретиной. А. Д. Бакулова. М.: Республика, 2004.

Ле Гофф 2003 - Ле Гофф Ж. Интеллектуалы в Средние века. СПб.: Издательский дом СПбГУ, 2003.

Лисанюк 2006 - Лисанюк Е. Н. Средневековый диспут // Логико-философские штудии. 2006. №. 4. С. 212-227.

Перельмутер 1991 - Перельмутер И. А. Грамматическое учение модистов // История лингвистических учений. Позднее Средневековье / под. ред. А. В. Десницкой. Л.: Наука, 1991. С. 7-66.

Савельев 2006 - Савельев А. Л. История идеи универсальной грамматики с древнейших времен и до Лейбница. СПб.: Издательство СПбГУ, 2006.

Фома 2006 - Фома Эрфуртский. Трактат о модусах обозначения, или Спекулятивная грамматика // Савельев А. Л. История идеи универсальной грамматики: с древнейших времен и до Лейбница. СПб: Издательство СПбГУ, 2006. C. $285-381$. 